\title{
Adjuvant vaginal cuff brachytherapy in surgically treated endometrial carcinoma patients - in view of the recent evidence
}

\author{
Krystyna Serkies, MD, PhD, Zuzanna Baczkowska-Waliszewska, MD \\ Department of Oncology and Radiotherapy, Medical University of Gdańsk, Gdańsk, Poland
}

\begin{abstract}
Vaginal cuff brachytherapy is an essential component of adjuvant post-operative therapy in endometrial carcinoma. Brachytherapy boost, as a part of adjuvant pelvic radiotherapy, including concomitant chemoradiotherapy combined with four cycles carboplatin/paclitaxel chemotherapy, is used in early-stage high-risk and advanced stage disease. This strategy is widely accepted and recommended by international guidelines, despite the fact that combined therapy has never been verified in randomized trials. Brachytherapy alone is the adjuvant treatment of choice for many patients with early-stage endometrial cancer, with high-intermediate features, replacing external beam pelvic radiotherapy. It provides equivalent vaginal control with a lower risk of toxicity, and minimal impact on health-related quality of life. Available evidence did not demonstrate the superiority of sole vaginal brachytherapy combined with three cycles of carboplatin/ paclitaxel chemotherapy, over the standard pelvic irradiation for patients with early-stage, high-intermediate-, and high-risk endometrial cancer. This article summarized the available evidence on the role of post-operative vaginal cuff brachytherapy in endometrial cancer patients. Additionally, the risk groups definition, some aspects of brachytherapy technique, and the importance of pathological and molecular risk factors for endometrial cancer risk stratification were presented. Furthermore, the role of brachytherapy according to the European Society of Gynecological Oncology/European Society for Radiotherapy and Oncology/European Society of Pathology 2021 guidelines for the management of patients with endometrial carcinoma was presented.

Key words: endometrial carcinoma, brachytherapy, radiotherapy, chemotherapy, chemoradiotherapy.

\section{Purpose}

Endometrial carcinoma (EC) is the most common gynecologic malignancy in developed countries, with rising incidence and mortality rates [1]. The majority of EC are classified as type 1 , related to exogenous estrogen exposure, typically with low- (G1) or intermediate-grade (G2) endometrioid histology (EEC). Most patients are diagnosed at an early stage (confined to the uterus or cervix, stage I or II), conveying a generally good prognosis. Approximately, only $15 \%$ to $20 \%$ of EC patients have an unfavorable prognosis and, besides loco-regional relapse, a higher risk of distant metastases, due to highgrade (G3), advanced stage, or/and non-endometrioid histologies (NEEC; type 2 EC, considered estrogen independent), such as serous, clear cell, or carcinosarcomas [2]. Hysterectomy with or without lymphadenectomy is the cornerstone of treatment for most EC patients. Two large, randomized trials failed to show any survival benefit associated with systemic nodal dissection in EC [3, 4]. However, the detection of pelvic and para-aortic lymph nodes disease affects staging, prognosis, and, possibly, post-operative treatment decisions. Based on the FIRES trial, sentinel lymph node (SLN) mapping is increasingly employed as a standard-of-care staging to evaluate nodal spread in EC [5, 6]. The clinical importance of pathologic ultrastaging as a part of SLN mapping to identify isolated tumor cells (ITCs) and micrometastases (American Joint Committee on Cancer staging sub-categorize ITCs $<0.2 \mathrm{~mm}$, micrometastases [0.2 to $2 \mathrm{~mm}$ ], and macrometastases [ $>2 \mathrm{~mm}]$ ) is not yet defined.

To guide decision-making with regard to adjuvant treatment and its associated morbidity, risk groups according to age, tumor type, and grade, depth of myometrial invasion (MI), presence of lymphovascular space invasion (LVSI), and stage were used in EC (Table 1) [2, 7-9]. These standard clinico-pathological risk factors impact on the risk for loco-regional relapse and distant metastases. Patients with International Federation of Gynecology and Obstetrics (FIGO) stage I and II disease are classified as low- (LR), intermediate- (IR), high-intermediate- (HIR), 
Table 1. Risk groups in endometrial cancer

\begin{tabular}{|c|c|c|c|c|}
\hline Risk group & $\begin{array}{c}\text { As per PORTEC-1 (2000) } \\
{[7]}\end{array}$ & As per GOG-99 (2004) [8] & $\begin{array}{c}\text { As per ESMO/ESGO/ } \\
\text { ESTRO consensus (2016) [2] }\end{array}$ & $\begin{array}{c}\text { As per ESGO/ESTRO/ESP } \\
\text { statement (2021) [9] }\end{array}$ \\
\hline Low & $\begin{array}{l}\text { Stage I EEC, any age, } \\
\text { G1-2, }<50 \% \mathrm{Ml}\end{array}$ & Stage I EEC, no MI & $\begin{array}{c}\text { Stage I EEC, G1-2, <50\% MI, } \\
\text { LVSI negative }\end{array}$ & $\begin{array}{l}\text { Stage I EEC, G1-2, < } 50 \% \text { MI, } \\
\text { LVSI negative or focal }\end{array}$ \\
\hline Intermediate & & & $\begin{array}{c}\text { Stage I EEC, G1-2, } \geq 50 \% \mathrm{MI} \\
\text { LVSI negative }\end{array}$ & $\begin{array}{l}\text { Stage I EEC, G1-2, } \geq 50 \% \mathrm{MI} \text {, } \\
\text { LVSI negative or focal } \\
\text { Stage I EEC, G3, <50\% MI, } \\
\text { LVSI negative or focal } \\
\text { Stage I NEEC, no MI }\end{array}$ \\
\hline $\begin{array}{l}\text { Low- } \\
\text { intermediate }\end{array}$ & $\begin{array}{c}\text { Stage I EEC, G1-2, } \\
\text { age }<60 \mathrm{y}, \geq 50 \% \mathrm{MI}\end{array}$ & $\begin{array}{c}\text { Stage I EEC, } \\
\text { not high-intermediate }\end{array}$ & & \\
\hline $\begin{array}{l}\text { High- } \\
\text { intermediate }\end{array}$ & $\begin{array}{c}\text { Stage I EEC, G3, } \\
\text { age } \geq 60 \mathrm{y},<50 \% \mathrm{Ml}\end{array}$ & $\begin{array}{c}\text { Stage I EEC, any age, with } \\
\text { all factors: G3, } \geq 66 \% \mathrm{MI} \text {, } \\
\text { and LVSI positive or age } \\
\geq 50 \text { with any two risk } \\
\text { factors listed above, or age } \\
\geq 70 \text { with any risk factors } \\
\text { listed above }\end{array}$ & $\begin{array}{c}\text { Stage I EEC, G3, < } 50 \% \mathrm{MI} \text {, } \\
\text { any LVSI } \\
\text { Stage I EEC, G1-2, any MI, } \\
\text { LVSI unequivocally positive }\end{array}$ & $\begin{array}{l}\text { Stage I EEC, substantial LVSI, } \\
\text { regardless of G and MI } \\
\text { Stage I EEC, G3, } \geq 50 \% \mathrm{MI} \text {, } \\
\text { regardless of LVSI status } \\
\text { Stage II }\end{array}$ \\
\hline High & $\begin{array}{l}\text { Stage I EEC, G3, } \\
\geq 50 \% \text { MI } \\
\text { Stage II-III EEC } \\
\text { Stage I-III NEEC }\end{array}$ & $\begin{array}{l}\text { Stage II-III EEC } \\
\text { Stage I-III NEEC }\end{array}$ & $\begin{array}{c}\text { Stage I EEC, G3, } \geq 50 \% \mathrm{MI} \text {, } \\
\text { any LVSI } \\
\text { Stage II } \\
\text { Stage III EEC, no residual } \\
\text { disease } \\
\text { NEEC } \\
\text { *Stage III residual disease, } \\
\text { stage IVA } \\
\text { Stage IVB }\end{array}$ & $\begin{array}{l}\text { Stage III-IVA EEC, no residual } \\
\text { disease } \\
\text { Stage I-IVA NEEC, MI present, } \\
\text { no residual disease }\end{array}$ \\
\hline
\end{tabular}

EEC - endometrioid endometrial cancer, NEEC - non-endometrioid endometrial cancer, MI-myometrial invasion, G - grade, LVSI - lymph-vascular space invasion, PORTEC - Post Operative Radiation Therapy in Endometrial Carcinoma trial, GOG - Gynecologic Oncology Group trial, ESMO/ESGO/ESTRO - European Society of Medical Oncology/European Society of Gynecological Oncology/European Society for Radiotherapy and Oncology, ESGO/ESTRO/ESP - European Society of Gynecological Oncology/European Society for Radiotherapy and Oncology/European Society of Pathology, " advanced/metastatic disease

and high-risk (HR). It should be mentioned that in comparison to the ESMO/ESGO/ESTRO (European Society of Medical Oncology/European Society of Gynecological Oncology/European Society for Radiotherapy and Oncology) consensus conference, risk category changes, especially HIR and HR definitions, which have been described in the most recently published guidelines by the ESGO/ ESTRO/ESP (European Society of Gynecological Oncology/European Society for Radiotherapy and Oncology/ European Society of Pathology) [9]. In addition to risk groups based on traditional features, EC prognostic risk groups in the molecular classification were presented.

Post-operative radiotherapy (RT) with or without chemotherapy (CT) carries the risk of morbidity, and there is no strong evidence of significant benefit in terms of cancer-related mortality and overall survival (OS). Additionally, the optimal adjuvant therapy, including the form of irradiation and the role of CT, is unclear. The aim of this article was to summarize and critically analyze the current available evidence on the role of post-operative vaginal brachytherapy (VBT) in EC patients, with special attention to combined RT and CT. Recently published first trial that addressed adjuvant exclusive VBT with CT was reported [10]. We also presented VBT fractionation schedules, the importance of proper pathology review, and future perspectives in particular risk group stratification to further improve patient recruitment for VBT.
Relevant literature was selected in PubMed database. The time period of the research included articles published from 1980 to January 2021, with no language restrictions (entries: 'endometrial cancer', 'radiotherapy', 'brachytherapy', 'chemotherapy', 'chemoradiation/ chemoradiotherapy', and 'randomized trial'), followed by cross-referencing from previously identified studies. Articles were selected by their relevance to the topic.

\section{Brachytherapy as a part of adjuvant pelvic radiotherapy and chemoradiotherapy}

Pelvic external beam radiotherapy (pEBRT) continues to be the classical form of RT, having been employed post-operatively for decades in EC patients. Adjuvant RT significantly reduces the risk of EC recurrence, specifically vaginal or pelvic relapse, but has not been shown to affect OS in any EC patient subset. For early-stage EC, the benefit of post-operative pEBRT was first demonstrated by Aalders et al. [11] in 1980 in a trial, which enrolled patients treated post-operatively with radium VBT, and in three more recent trials comparing adjuvant pEBRT vs. observation [7, 8, 12-14]. Of those, VBT boost was used in only one that included IR and HR $(25 \%$ and $20 \%$, respectively) EEC patients [12]. VBT was used, in accordance with local practice, in $53 \%$ of all patients, and in $52 \%$ in the observation arm. The two remaining trials, that estab- 
lished the role of pEBRT in local control of early-stage EC, included PORTEC-1 (Post Operative Radiation Therapy in Endometrial Carcinoma) and GOG-99 (Gynecologic Oncology Group), did not employ a VBT boost. These trials enrolled LR and IR EEC patients. In contrast to GOG-99, the PORTEC- 1 trial excluded HR patients (with $\geq 50 \% \mathrm{MI}$, G3 tumors or cervical involvement), and did not mandate staging lymphadenectomy. Adjuvant radiation decreases pelvic recurrence by $50 \%$ to $70 \%$; although, the absolute benefit is limited for patients with LR or IR disease. Without RT, the most common site of relapse was the vaginal vault and less frequently, the pelvic or para-aortic lymph nodes or distant sites, such as the peritoneal cavity or lungs $[7,8]$. The greatest benefit from adjuvant pEBRT was achieved in the HIR subset of patients (Table 1). Long-term outcomes confirm the relevance of HIR criteria for treatment selection and the lack of benefit from pEBRT in patients with LR and IR [13]. The actuarial loco-regional recurrence (LRR) rates at 15 years were 6\% for pEBRT vs. $15.5 \%$ for no additional treatment (NAT) $(p<0.0001)$. The most common type of LRR in the NAT group was vaginal recurrences $(11.0 \%$ of a total of $15.5 \%)$. Multivariate analysis confirmed the prognostic significance of G3, age $>60$ years and $\mathrm{MI}>50 \%$ for the risk of LRR. The 15-year rates of distant metastases were $9 \%$ vs. $7 \%$ $(p=0.25)$, and the OS was $52 \%$ vs. $60 \%(p=0.14)$ and $41 \%$ vs. $48 \%(p=0.51)$ for all patients and for those with HIR criteria, respectively.

Given the risk of distant metastasis in both HR and HIR early-stage patients and in those with locally advanced disease, the implementation of adjuvant $\mathrm{CT}$ with or without RT was the subject of investigation. There were no survival differences between IR or HR (stage I-III) patients assigned to cyclophosphamide/doxorubicin/ cisplatin (CAP) CT, or sequential CAP with pEBRT than standard pEBRT alone (without planned VBT) in earlier trials [15-17]. The more recent trials using CT in addition to RT are summarized in Table 2. Of note, in these trials, the use of VBT as a part of RT was left to the discretion of investigator, and was performed only in $38-58 \%$ of cases.

The Nordic Society of Gynecological Oncology/European Organization for Research and Treatment of Cancer (NSGO/EORTC/Mario Negri Gynecologic Oncology Group [MaNGO]) study was a combined analysis of two independent randomized trials [18]. It was the first trial to show recurrence-free survival (RFS) improvement with combined adjuvant RT and CT. There was a significant clinical heterogeneity between these trials with regard to clinical risk, tumor histology, sequencing (CT before or after pEBRT), type of $\mathrm{CT}$, and number of adjuvant $\mathrm{CT}$ cycles. Stage I, II disease was present in $78 \%$ of patients, $88 \%$ in the NSGO study, and $26 \%$ had NEEC. VBT boost was used in $38 \%$ of the study population, equally in both arms. The addition of adjuvant CT to pelvic RT significantly improved the 5-year progression-free survival (PFS) rate, and increased by $45 \%$ the risk reduction for cancer-specific survival (CSS). There was a non-significant $7 \%$ benefit in 5 -year OS with CT. The subset of patients with NEEC histology did not seem to benefit from CT, and there was no difference in treatment effect by stage.
The recently reported PORTEC-3 study evaluated concurrent chemoradiation (CRT) with outback CT in patients with HR early-stage and stage III EC [19-21]. This study included $55 \%$ of patients with true (based on upfront pathology review) HR early-stage disease. Stage III disease was present in $43 \%$ of patients, $25 \%$ had NEEC, and $28 \%$ had G3 disease. The VBT boost, used in case of glandular or stromal cervical involvement, was employed in both arms in nearly half of the study population. The addition of CT led to a significant improvement of the 5-year failure-free survival (FFS) rate and PFS, with a trend towards improved OS. Vaginal recurrence was developed in $2.1 \%$ of the patients in both arms. On subset analysis, the FFS benefit for CT was greatest for patients with stage III disease (consisting of a large proportion of the study population), and did not extend to stage I and II disease. Patients with serous cancer, who represented $16 \%$ of the study group, had significantly lower FFS rate than those with other histologic sub-types. A majority of recurrences were at distant sites. The rate of isolated pelvic recurrence was low ( $1 \%$ and $2 \%$ with and without $C T$, respectively), reflecting the impact of $\mathrm{RT}$ in both arms. Adverse events (AEs) were significantly more common in the CRT arm (61\% vs. $13 \%$ grade 3 and 4$)$. Grade 2 AEs were also more common in the CRT arm; grade 2 or worse neuropathy at 5 years occurred in $6 \%$ vs. $0 \%$ of the patients, respectively [19].

The GOG-258 trial compared CRT used in the PORTEC-3 trial, with CT consisting of carboplatin/ paclitaxel alone in a group of locally advanced EC [22]. Nearly $75 \%$ of the patients presented EEC with lymph-node involvement, and the majority of patients underwent full staging. The VBT boost allowed in the CRT arm was performed in $58 \%$ of the cases. In the CT arm, $85 \%$ of the patients received all six cycles. After a median follow-up of 47 months, significantly higher rates of pelvic and para-aortic nodal recurrences were seen in the CT arm, whereas in the CRT arm, there was a trend towards more distant metastases as a first relapse. There were no differences between the arms regarding RFS and OS, and the acute toxicity was lower with CRT. Severe AEs, mostly gastrointestinal (GI), blood, and bone marrow, and constitutional symptoms occurred in $58 \%$ and $63 \%$ of the patients. This trial included $18 \%$ of serous cancers cases, but sub-group analysis did not identify a sub-set that may have benefited from CRT compared to CT.

\section{Brachytherapy as a sole form of adjuvant radiotherapy}

The findings from the PORTEC-1 and GOG-99 trials reported that $70 \%$ of loco-regional recurrences in the observation arm were isolated vaginal recurrences, and were the base for exploring a strategy of adjuvant VBT alone. In LR (FIGO 1988; stage IA-B, G1-2) EEC, there was no impact of post-operative VBT on the overall recurrence rate $(4 \%$ in total), including vaginal $(1.2 \%$ vs. $3.1 \%$ in the control group; $p=0.114$ ) [23]. There was also no survival improvement. Randomized trials of post-operative VBT alone or combined with CT for EC patients with risk fea- 
Table 2. Recent randomized trials of pelvic external beam radiotherapy combined with chemotherapy for endometrial cancer patients treated with total abdominal hysterectomy with bilateral salpingo-oophorectomy

\begin{tabular}{|c|c|c|c|}
\hline Study & $\begin{array}{c}\text { MaNGO ILIADE-III and NSGO/ } \\
\text { EORTC, } 2010 \text { [18] }\end{array}$ & PORTEC-3, 2016 [19-21] & GOG-258, 2019 [22] \\
\hline $\begin{array}{l}\text { Study population } \\
\text { (number of cases) }\end{array}$ & $\begin{array}{c}\text { FIGO (1988) stage I, IIA, IIIA } \\
\text { III }{ }^{\mathrm{b}} \text { EC } \\
\text { NSGO/EORTC ( } n=378) \text { I-III } \\
\text { EC with risk factors (G3, deep } \\
\text { invasion, or NEEC), } 90 \% \text { had } \\
\text { stage I Italian trial: } n=156, \\
\text { stage II, III EEC } \\
(n=534)\end{array}$ & $\begin{array}{c}\text { FIGO (2009) stage I EEC with HR } \\
\text { factors (G3 with deep invasion or } \\
\text { extensive LVSI), excluding CS, } \\
\text { stage II, III EEC, stage I-III NEEC } \\
43 \% \text { had stage III } \\
28 \% \text { had G3 EEC } \\
(n=660)\end{array}$ & $\begin{array}{l}\text { FIGO (2009) stage III, IVA EC, excluding } \\
\text { CS, stage I, II NEEC with positive peri- } \\
\text { toneal washing } \\
\text { Up to } 2 \mathrm{~cm} \text { of residual disease } \\
\text { post-surgery allowed; nearly } 98 \% \text { had } \\
\text { no gross residual disease } \\
\qquad(n=736)\end{array}$ \\
\hline Histology & $\begin{array}{l}\text { Endometrioid (71\%) } \\
\text { Serous (14\%) } \\
\text { Clear cell (12\%) }\end{array}$ & $\begin{array}{l}\text { Endometrioid ( } 75 \% \text { and } 74 \%) \\
\text { Serous ( } 16 \% \text { and } 16 \%) \\
\text { Clear cell ( } 9 \% \text { and } 10 \%)\end{array}$ & $\begin{array}{c}\text { Endometrioid } 68.6 \% \text { and } 70.7 \% \\
\text { (totally G1 45.7\%, G2 60\%, G3 34\%) } \\
\text { Serous (17.8\% and } 17.8 \%) \\
\text { Clear cell ( } 2.7 \% \text { and } 3.3 \%)\end{array}$ \\
\hline Nodal staging & $\begin{array}{c}\text { Optional } \\
\text { LND in } 26 \%\end{array}$ & $\begin{array}{c}\text { Optionalc } \\
\text { LND in } 57 \% \text { and } 58 \%\end{array}$ & $\begin{array}{c}\text { Optionald }^{\mathrm{d}} \\
\text { LND in more than } 94 \%\end{array}$ \\
\hline Risk group & $H R$ & $H R$ & $\mathrm{HIR}$ and $\mathrm{HR}$ \\
\hline Randomization & $\begin{array}{l}\text { pEBRT ( } \geq 44 \text { Gy) vs. sequential } \\
\text { pEBRT + CT (platinum-based) } \\
4 \text { cycles or } 3 \text { cycles of doxoru- } \\
\text { bicin/cisplatin (Italian study) }\end{array}$ & $\begin{array}{l}\text { pEBRT (48.6 Gy/1.8 Gy fx) vs. CRT } \\
\text { (pEBRT with } 2 \times \text { CP), followed by CT } \\
\text { carboplatin AUC 5/paclitaxel } \\
175 \mathrm{mg} / \mathrm{m}^{2} / 3 \text { h q } 21 \text { days } \times 4 \text { cycles }\end{array}$ & $\begin{array}{c}\text { CRT (45 Gy pEBRT with } 2 \times \text { CPf), } \\
\text { followed by CT carboplatin AUC 5-6/ } \\
\text { paclitaxel } 175 / \mathrm{mg} / \mathrm{m}^{2} / 3 \text { h with G-CSF } \\
\text { support q } 21 \text { days } \times 4 \text { cycles vs. CT } \\
\text { carboplatin AUC } 6 / \text { paclitaxel } \\
175 \mathrm{mg} / \mathrm{m}^{2} / 3 \mathrm{~h} \text {, q } 21 \text { days } \times 6 \text { cycles }\end{array}$ \\
\hline VBT boost & $\begin{array}{c}\text { Overall in 38\% } \\
\text { RT arm: } 39 \% \text { and } 28 \% \\
\text { RT + CT arm: } 44 \% \text { and } 31 \% \\
\text { in EORTC and Italian trial, } \\
\text { respectively }\end{array}$ & $\begin{array}{c}46 \% \text { and } 48 \% \\
(\text { HDR } 10 \mathrm{~Gy} / 5 \mathrm{~mm} / 2 \mathrm{fx})\end{array}$ & $58 \%$ in CRT arm only \\
\hline Results & 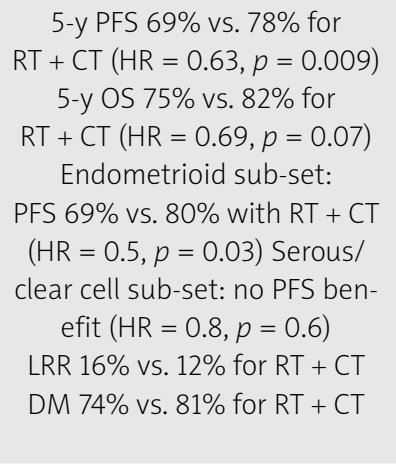 & $\begin{array}{c}5 \text {-y PFS } 69 \% \text { vs. } 76 \% \text { for } \\
\text { CRT (HR }=0.7, p=0.016 \text { ) } \\
5 \text {-y OS } 76 \% \text { vs. } 81 \% \text { for } \\
\text { CRT (HR }=0.7, p=0.034 \text { ) } \\
5 \text {-y FFS } 58 \% \text { vs. } 71 \% \text { for CRT for } \\
\text { stage III (HR }=0.61, p=0.011 \text { ), } \\
77 \% \text { vs. } 81 \% \text { for CRT (HR }=0.87 \text {, } \\
p=0.54 \text { ) for stage I and II } \\
\text { Pelvic recurrence: } 8.8 \% \text { vs. } 5.5 \% \text { for } \\
\text { CRT (HR }=0.63, p=0.11 \text { ) } \\
\text { DM } 29.4 \% \text { vs. } 22.1 \% \text { for CRT } \\
\text { (HR }=0.75, p=0.057 \text { ) }\end{array}$ & $\begin{array}{l}\text { 5-y RFS 59\% vs. 58\% for CT } \\
\text { (HR =0.9) } \\
5 \text {-y OS 70\% vs. } 73 \% \text { for CT (NS) } \\
\text { Vaginal recurrence: } 2 \% \text { vs. } 7 \% \text { for } \\
\text { CT (HR = 0.36) } \\
\text { Pelvic and para-aortic lymph-node } \\
\text { recurrence: } 11 \% \text { vs. } 20 \% \text { for } \\
\text { CT (HR = 0.43) } \\
\text { DM 27\% vs. } 21 \% \text { for CT }(H R=1.36)\end{array}$ \\
\hline
\end{tabular}

a IIIA - only positive peritoneal fluid cytology, ${ }^{b}$ IIIC - only positive pelvic lymph nodes without macroscopic residual tumor, ${ }^{c}$ lymph node debulking and para-aortic lymph node sampling recommended in cases of macroscopic-positive lymph nodes, ${ }^{d}$ pelvic and para-aortic biopsy or dissection, median number of 13 pelvic and 3 para-aortic nodes removed, ${ }^{e}$ doxorubicin/epirubicin with cisplatin (vast majority), paclitaxel/carboplatin, doxorubicin/cisplatin/carboplatin doxorubicin/paclitaxel, ${ }^{f}$ cisplatin $50 \mathrm{mg} / \mathrm{m}^{2}$ on day 1 and 29 of RT with volume-directed EBRT $45 \mathrm{~Gy}$, IMRT (intensity-modulated radiotherapy) in 30\%, EC - endometrial cancer, G - grade, NEEC - non-endometrioid endometrial cancer (serous or clear cell histology); EEC - endometrioid endometrial cancer, HR - high-risk, LVSI - lymph-vascular space invasion, CS - carcinosarcoma, LND - lymph node dissection, HIR - high-intermediate-risk, $p E B R T$ - pelvic external beam radiotherapy, CT - chemotherapy, fx - fractions, CRT-concomitant chemoradiotherapy, CP-cisplatin $50 \mathrm{mg} / \mathrm{m}^{2}$ on day 1 and 29 of RT, AUC - area under curve, G-CSF - granulocyte colony-stimulating factor, $q$ - every, VBT - vaginal brachytherapy, RT +CT - radiotherapy combined with chemotherapy, HDR - high-dose-rate, PFS - progression-free survival, HR - hazard ratio, OS - overall survival, LRR - loco-regional recurrence, DM - distant metastasis, FFS - failure-free survival, RFS - recurrence-free survival

tures are presented in Table 3. The PORTEC-2 trial compared pEBRT and VBT in patients with early-stage EEC with HI risk features [24-26]. Exclusion criteria included serous or clear cell carcinoma, staging lymphadenectomy, and $>8$ weeks interval between surgery and RT. Suspicious lymph nodes found at surgery were selectively removed. After 5 years, the rates of vaginal recurrence in both treatment's arms were low (1.8\% for VBT and $1.6 \%$ for pEBRT), without a difference in OS and disease-free survival (DFS) [24]. VBT was associated with a greater risk of pelvic (non-vaginal) recurrence compared to pelvic radiation ( $3.8 \%$ vs. $0.5 \%)$, but with a lower risk of GI toxicity (acute grade 1 and 2 in $12.6 \%$ vs. 53.8\%, respectively) and improved quality of life. The 10 -year vaginal recurrence rate in the entire study population was $3.4 \%$ and $2.4 \%$, respectively $(p=0.55)[26]$. Although the risk 
Table 3. Recent randomized trials of vaginal brachytherapy alone or combined with chemotherapy for endometrial cancer patients with risk features, treated with total abdominal hysterectomy with bilateral salpingooophorectomy

\begin{tabular}{|c|c|c|c|}
\hline Study & Swedish, $2009[27,28]$ & PORTEC-2, 2010 [24-26] & GOG-249, 2019 [10] \\
\hline $\begin{array}{l}\text { Study population } \\
\text { (number of cases) }\end{array}$ & $\begin{array}{c}\text { FIGO (1988) stage I EEC with at } \\
\text { least one medium risk factor } \\
(\geq 50 \% \mathrm{MI}, \mathrm{G} 3 \text {, nuclear aneuploidy) } \\
\geq 50 \% \mathrm{MI} \text { in } 52.7 \% \text { and } 55.1 \% \\
\mathrm{G} 1 \text { in } 36.4 \% \text { and } 39.2 \% \\
\mathrm{G} 2 \text { in } 50.8 \% \text { and } 49.8 \% \\
\text { G3 in } 12.9 \% \text { and } 11 \% \\
(n=527)\end{array}$ & $\begin{array}{c}\text { FIGO (1988) stage I EEC } \\
(\mathrm{G} 1-2, \geq 50 \% \mathrm{MI} \text {, age }>60 \mathrm{y} \text {, or G3, } \\
<50 \% \mathrm{MI} \text {, age }>60 \mathrm{y}) \text {, stage IIA, } \\
\text { any age except G3 and }>50 \% \mathrm{MI} \\
(n=427)\end{array}$ & $\begin{array}{c}\text { FIGO (2009) stage I EEC with } \\
\text { high-intermediate risk factors } \\
\text { (risk factor: > } 70 \text { y and one, } \\
>50 \text { y and two, > } 19 \text { y, and three } \\
\text { of the following risk factors: G2-3, } \\
>50 \% \text { MI, LVSI +), stage II EEC, } \\
\text { stage I-II NEEC } \\
\text { (negative peritoneal cytology) } \\
\text { stage I in } 75 \% \text {, stage II in } 24.6 \% \\
(n=601)\end{array}$ \\
\hline Histology & Endometrioid & Endometrioid & $\begin{array}{l}\text { Endometrioid (71\%; G1 17.6\%, } \\
\text { G2 35.3\%, G3 20.8\%) } \\
\text { Serous (14.6\%) } \\
\text { Clear cell (4.7\%) }\end{array}$ \\
\hline Risk group & Medium $^{a}$ & HIR & $H I R, H R$ \\
\hline Nodal staging & LN sampling & $\begin{array}{l}\text { No routine; sampling of suspicious } \\
\text { LN }\end{array}$ & $\begin{array}{l}\text { Bilateral pelvic and para-aortic LND } \\
\text { as recommended done in } 90 \% \text { b }\end{array}$ \\
\hline Randomization & VBT \pm pEBRT (46 Gy/1.8-2 Gy) & pEBRT (46 Gy/2 Gy) vs. VBT & $\begin{array}{l}\text { pEBRT ( } 45-50.4 \text { Gy } / 1.8 \text { Gy) } \text {, } 32 \% \text { re- } \\
\text { ceived VBT boost vs. VBT followed } \\
\text { by CT carboplatin AUC } 6 / \text { paclitaxel } \\
175 \mathrm{mg} / \mathrm{m}^{2} / 3 \mathrm{~h}, \mathrm{q} 21 \text { days } \times 3 \text { cycles }\end{array}$ \\
\hline VBT & $\begin{array}{l}\text { HDR } 3 \text { Gy for } 6 \mathrm{fx} \text { or } 5.9 \text { Gy for } 3 \mathrm{fx} \text {, } \\
\text { or LDR } 20 \text { Gy/1 fx, at } 5 \mathrm{~mm} \text { depth }\end{array}$ & $\begin{array}{l}\text { HDR } 21 \text { Gy in } 3 \mathrm{fx} \text { of } 7 \mathrm{~Gy} \text {, or an } \\
\text { equivalent dose using LDR or MDR, } \\
\text { at } 5 \mathrm{~mm} \text { depth }\end{array}$ & $\begin{array}{l}\text { HDR } 6 \text { to } 7 \mathrm{~Gy} / 3 \mathrm{fx} \text { at } 5 \mathrm{~mm} \text { depth, } \\
\text { or } 10 \text { to } 10.5 \mathrm{~Gy} / 3 \mathrm{fx} \text {, or } 6 \mathrm{~Gy} / 5 \mathrm{fx} \text { at } \\
\text { the vaginal surface, or LDR } 65 \text { to } \\
70 \mathrm{~Gy} / 1-2 \mathrm{fx} \text { at the vaginal surface }\end{array}$ \\
\hline Results & $\begin{array}{l}5-y \text { crude rates of recurrence of } \\
5.7 \% \text { for pEBRT + VBT vs. 10.3\% for } \\
\text { VBT alone ( } p=0.052) \\
5 \text {-y LRR } 1.5 \% \text { for } p E B R T+\text { VBT } \\
\text { Vs. } 5 \% \text { for VBT alone }(p=0.013) \\
5 \text {-y OS } 89 \% \text { for EBRT + VBT vs. } 90 \% \\
\text { for VBT alone }(p=0.548) \\
\text { DM 4.6\% for EBRT + VBT vs. } 6.5 \% \\
\text { for VBT alone }(p=0.334)\end{array}$ & $\begin{array}{l}5 \text {-y rates of vaginal recurrence } \\
\text { of } 1.6 \% \text { vs. } 1.8 \% \text { for VBT } \\
\quad(H R=0.78, p=0.74) \\
5 \text {-y LRR (vaginal or pelvic recur- } \\
\text { rence, or both) } 2.1 \% \text { vs. } 5.1 \% \text { for } \\
\text { VBT (HR }=2.08, p=0.17) \\
10 \text {-y pelvic recurrences } 0.9 \% \text { vs. } \\
6.3 \% \text { for VBT ( } p=0.004) \text {, of these } \\
0.5 \% \text { vs. } 2.5 \% \text { were isolated pelvic } \\
\text { relapse ( } p=0.10 \text { ), the remaining } \\
\text { combined with DM } \\
10 \text {-y DM } 8.9 \% \text { vs. } 10.4 \% \text { for VBT } \\
(p=0.45) \\
\text { 10-y OS } 69.5 \% \text { vs. } 67.6 \% \text { for VBT } \\
(p=0.72)\end{array}$ & $\begin{array}{l}\text { 5-y cumulative incidence of pelvic } \\
\text { or para-aortic nodal recurrences of } \\
4 \% \text { for RT vs. } 9 \% \text { for VBT + CT } \\
\text { (HR }=0.47) \\
\text { No difference in incidence of DM } \\
\text { (18\%) (HR of EBRT relative to VBT } \\
+ \text { CT, 1.0) }\end{array}$ \\
\hline $\begin{array}{l}\text { Vaginal recur- } \\
\text { rence }\end{array}$ & $\begin{array}{l}5-y \text { crude rates of vaginal recur- } \\
\text { rence of } 1.9 \% \text { for } p E B R T+\text { VBT vs. } \\
2.7 \% \text { for VBT alone }(p=0.555)\end{array}$ & $\begin{array}{l}\text { 10-y vaginal recurrence in } 2.4 \% \\
\text { and } 3.4 \% \text { for VBT ( } p=0.55) \text { in the } \\
\text { whole group and of } 3.1 \% \text { and } 2.7 \% \\
\text { for VBT in the confirmed HIR group }\end{array}$ & $\begin{array}{l}\text { No difference in incidence of vagi- } \\
\text { nal recurrences }(2.5 \%)(H R \text { of EBRT } \\
\text { relative to VBT }+C T, 1.0)\end{array}$ \\
\hline
\end{tabular}

of pelvic recurrence was significantly higher in the VBT group $(6.3 \%$ vs. $0.9 \%)$, the majority of these patients presented with simultaneous distant metastases, resulting in similarly low rates of isolated pelvic recurrence in both treatment's arms. There were no differences in 10-year rates of distant metastases and OS. In the confirmed HIR cohort, the 10-year vaginal recurrence rates for VBT vs. pEBRT were $2.7 \%$ and $3.1 \%$, respectively $(p=0.78)$, and the pelvic recurrence rates $7.4 \%$ and $1.2 \%$, respectively $(p=0.01)$. Analysis of the long-term results within the 
HIR-confirmed population showed no significant differences compared to the intention to treat analysis. The long-term results of the PORTEC-2 trial confirmed VBT as the post-operative treatment of choice for HIR EC. Pelvic EBRT may provide better pelvic control in a small sub-group of patients with unfavorable risk factors (substantial LVSI, L1CAM [L1 cell adhesion molecule] expression or p53 expression).

A Swedish and Norwegian Radium Hospital trial compared VBT alone versus pEBRT combined with a VBT boost in patients with medium-risk EEC, and as defined by authors, included neither LR nor HR cases $[27,28]$. After a median follow-up of 62 months, pelvic recurrences (exclusively vaginal) were reduced by $93 \%$ by the addition of EBRT to VBT. The 5-year loco-regional relapse rates were $1.5 \%$ vs. $5 \%$, with crude rates of vaginal recurrence of $1.9 \%$ vs. $2.7 \%$, respectively. Significant loco-regional control benefit with combined RT did not translate into OS improvement and quality of life results that favored sole VBT. Deep MI, but not grade or DNA ploidy, was a significant prognostic factor in this medium-risk group of EEC patients. Both therapies were well tolerated, with serious (grade 3 ) late AEs of less than $2 \%$. There was, however, a significant difference in favor of VBT alone.

In the recent GOG-249 phase III superiority trial, patients with early-stage HI- and HR-EC were randomly assigned to pEBRT, with either standard 4-field techniques 3D conformal or intensity-modulated radiotherapy (IMRT) alone, or VBT followed by three cycles of carboplatin/ paclitaxel CT (VBT + CT) [10]. HIR was defined by the GOG-99 criteria. Of the enrolled patients, 20\% had G3 EEC, $15 \%$ serous, and 5\% clear-cell carcinoma. A cuff BT boost permitted in the cases with cervical involvement or serous or clear cell histology, was performed in $32 \%$ of the patients. CT began up to 3 weeks from VBT initiation. At a median follow-up of 53 months, there was no difference in RFS or OS between treatment's arms, and VBT with CT was associated with more frequent and severe $(\geq$ grade 3 in $13 \%$ and $12 \%$ ) acute toxicity. CT also led to higher rates of neurotoxicity (returned to baseline at 14 months) and fatigue compared with pEBRT; these findings are in line with the PORTEC-3 study. Pelvic or para-aortic nodal recurrences were more common with VBT plus CT (9\% vs. $4 \%$ ), although $90 \%$ of the patients experienced a negative staging lymphadenectomy. Vaginal or distant recurrences within 5 years after finishing the treatment developed in approximately $2.5 \%$ and $18 \%$ of the patients in each arm, respectively. As CT was less effective than pelvic radiation in providing loco-regional control and did not decrease the risk of distant metastases, the authors concluded that pEBRT should remain the standard adjuvant treatment for early-stage HR disease. Beside the heterogenous patients' population by tumor sub-type, the only three cycles of systemic therapy administered in this trial could be considered to be sub-optimal.

\section{Vaginal brachytherapy technique}

VBT should be applied as soon as the vaginal cuff is healed, preferably 6-8 weeks after surgery, and no later than 12 weeks. The dose depends on the use of pEBRT, and should be prescribed to the vaginal surface or at a depth of $5 \mathrm{~mm}$ from the vaginal surface. Whenever available, image-guided RT should be used. The optimal VBT fractionation schedule, especially used as monotherapy, and the extent of vaginal treatment volume remain to be established. In general, the target for VBT after hysterectomy should be no more than the upper two-thirds of the vagina, and its longer segment may be treated in selected cases, including those with extensive LVSI or positive margins [29].

In the above-mentioned trials, exclusive VBT was delivered with a vaginal cylinder to the proximal half or the proximal two-thirds of the vagina in the PORTEC-2 and Swedish trials, respectively. Vaginal treatment length was not specified, but was generally 3 to $5 \mathrm{~cm}$ in the GOG-249 study [10]. High-dose-rate (HDR) (85\%), medium-dose-rate (MDR, $1 \mathrm{~Gy} / \mathrm{h}$ ), and low-dose-rate (LDR) (0.5-0.7 Gy/h) equipment was employed, and the total dose of 21 Gy with 7 Gy per each fraction, delivered once a week was prescribed at $5 \mathrm{~mm}$ depth in the PORTEC-2 trial [24]. The total doses in the Swedish study ranged between 17.7 and $20 \mathrm{~Gy}$ (EQD2 10 , the equivalent dose in $2 \mathrm{~Gy}$ fractions, $\alpha / \beta=10$ ), with 19.5 to $23.5 \mathrm{~Gy}$ at a depth of $5 \mathrm{~mm}$ and 29.3 to $35.3 \mathrm{~Gy}$ at the surface of the applicator, and were delivered with HDR or LDR (one center) equipment [27]. In the GOG-249 trial, the patients assigned to VBT + CT received cuff VBT during a HDR or LDR (4-10 Gy/h), prescribed at $5 \mathrm{~mm}$ depth or at the vaginal surface [10].

The most commonly employed VBT regimen is that proposed by the PORTEC-2 trial, including 21 Gy with three 7 Gy fractions, delivered once a week using ${ }^{192} \mathrm{Ir}$ HDR unit. However, there is a large variability in fractionation, total dose, and dose intensity [30-32]. Samples of applied fractionation of exclusive HDR-VBT reported in the literature, and the volume of vagina treated are presented in Table 4 [24, 33-38]. The shortened overall treatment time of exclusive VBT consisting of 21 Gy total dose at $5 \mathrm{~mm}$ in 3 fractions, every other day, for one week, was reported as safe [34].

The recent National Comprehensive Cancer Network (NCCN) guidelines for exclusive HDR-VBT, apart from $7 \mathrm{~Gy} \times 3$ fractions prescribed at a depth of $5 \mathrm{~mm}$ from the vaginal surface, also smaller fraction sizes, e.g., $6 \mathrm{~Gy} \times$ 5 fractions or $5.5 \mathrm{~Gy} \times 4$ fractions were included, which may limit toxicity in selected cases [29]. When HDR-VBT is used as a boost to EBRT, 2 to 3 fractions of 4-6 Gy prescribed to the vaginal mucosa are commonly used.

\section{Improving patient selection for brachytherapy}

Tumor pathology is crucial for risk stratification in EC. In the PORTEC- 1 and 2 trials, pathology review showed that $24 \%$ and $14 \%$ of patients, respectively, were in retrospect ineligible, compared to $8 \%$ for the PORTEC-3 trial $[14,26,39]$. Differences in eligibility were often caused by the shift from G2 to G1. In the PORTEC-1 study, central pathology review showed G1 disease in 60\% compared to $21 \%$ in local assessment. For HR-EC in the PORTEC-3, central upfront pathology review changed histological type, grade, or other characteristics in $43 \%$ of the patients 
Table 4. Schedules of post-operative high-dose-rate vaginal brachytherapy (HDR-VBT) used as monotherapy in endometrial cancer patients

\begin{tabular}{lccc}
\hline Author [ref.] & Dose/fractionation/prescription & Frequency & Volume of vagina treated \\
\hline Alektiar et al. [33] & $7 \mathrm{~Gy}$ or $6 \mathrm{~Gy} \times 3 \mathrm{fx} / 5 \mathrm{~mm}$ & q 2-week & Upper half to two-thirds \\
\hline De Sanctis et al. [34] & $7 \mathrm{~Gy} \times 3 \mathrm{fx} / 5 \mathrm{~mm}$ & q 2-day (one week) & Upper third $(3 \mathrm{~cm})$ \\
\hline Horowitz et al. [35] & $7 \mathrm{~Gy} \times 3 \mathrm{fx} / 5 \mathrm{~mm}$ & q 2-week & Proximal $5 \mathrm{~cm}$ \\
\hline Laliscia et al. [36] & $7 \mathrm{~Gy} \times 3 \mathrm{fx} / 5 \mathrm{~mm}$ & q week & Proximal $5 \mathrm{~cm}$ \\
\hline Landrum et al. [37] & $7 \mathrm{~Gy} \times 3 \mathrm{fx} / 5 \mathrm{~mm}$ b & q at least 72 hours & Upper half $(3-5 \mathrm{~cm})$ \\
\hline Nout et al. [24] & $7 \mathrm{~Gy} \times 3 \mathrm{fx} / 5 \mathrm{~mm}$ & q week & Upper two-thirds \\
\hline Sunil et al. [38] & $6.5 \mathrm{~Gy} \times 4 \mathrm{fx} / 5 \mathrm{~mm}$ & q week & Upper half
\end{tabular}

a for grade 3 tumors, most of the vaginal length was treated, ${ }^{b}$ plus chemotherapy (carboplatin/paclitaxel), HDR-VBT - high-dose-rate vaginal brachytherapy, $q$-every, fx-fractions

[39]. The greatest discrepancies between original and central pathology were found for the histological type $(15 \%)$ and grade $(20 \%)$.

LVSI is associated with the risk of (microscopic) nodal metastases, higher rates of both pelvic and distant failures, and lower survival, both in the presence and absence of lymph node metastases [40]. Using a 3-tiered approach, any degree of LVSI was identified in approximately $14 \%$ of the patients in the PORTEC-1 and 2 studies [41]. The presence of substantial diffuse or multifocal (not focal) LVSI found in $4.8 \%$ of the patients, had the strongest impact on the risk of distant metastasis (hazard ratio (HR) $=4.5$ ), and was an independent prognostic factor for pelvic regional recurrence $(\mathrm{HR}=6.2)$. Of note, VBT (as studied in PORTEC-2) did not impact the risk of recurrence in this cohort, justifying the exploration of systemic treatment options. The 10-year follow-up of the PORTEC-2 study found that beside extensive LVSI, higher p53 expression and L1CAM expression were associated with higher rates of pelvic recurrence and distant metastases [26]. Central pathology review performed in $97.4 \%$ of the enrolled patients (combined with molecular analysis) confirmed HIR status in $82.7 \%$ of PORTEC-2 cases, while $8.2 \%$ and 9.1\% were HR and LR, respectively. Among confirmed HIR patients, a sub-group of 50 women presented with any of the unfavorable risk features, including substantial LVSI, p53-mutant and/or L1CAM expression, with 17.2\% in the VBT group and $12 \%$ in the pEBRT group [26]. In the confirmed HIR patients, substantial LVSI was found to be a very strong independent risk factor for pelvic and distant recurrence $(\mathrm{HR}=8.73, p=0.005$, and $\mathrm{HR}=5.36$, $p=0.001$, respectively), and for EC-related survival (HR $=7.16, p<0.001)$, L1CAM expression and p53-mutant expression were significant prognostic factors for distant recurrence $(\mathrm{HR}=5.05, p=0.006)$ and CSS $(\mathrm{HR}=3.3$, $p=0.015)$. The proportion of patients with LVSI was not reported in the GOG-249 trial that assessed VBT in combination with CT [10]. Currently, LVSI status is a required component of the standard pathology report [9]. It should be unequivocal, and reported as focal or extensive/substantial (multifocal or diffuse arrangement of LVSI or presence of tumor cells in five or more vessels).

Since 2013, based on a comprehensive molecular/genetic analysis of EC (EEC as a vast majority of cases) of Cancer Genome Atlas (TCGA), four molecular sub-classes were defined, such as POLE-mutated (mutations in the exonuclease domain of DNA polymerase epsilon gene) with exceptionally good prognosis, TP53-mutated serous-like cancers with unfavorable prognosis, and intermediate prognosis cancers with microsatellite instability or without specific molecular profile [42]. Apart from p53 expression as a surrogate marker, microsatellite instability (MSI) can be assessed by immunohistochemical (IHC) loss of one or more of the MMR (mismatch repair) proteins. MMR-deficient tumors are known to be highly immunogenic with upregulation of immune checkpoints including the programmed death 1 (PD-1) pathway. ProMisE (proactive molecular risk classifier for endometrial cancer) that evaluates MMR and p53 by IHC, and sequencing of the exonuclease domain of POLE, may provide prognostic information [43]. Its predictive ability must be verified in a prospective manner. According to the authors of the ESGO/ESTRO/ESP 2021 guidelines, the decision to use molecular classification in all EC cases in the sub-set of G3 or HR tumors or in none of the cases, depends on the availability of resources and the decision of a multi-disciplinary team of each center [9]. If available, molecular classification data, including information regarding the methods used for IHC as well as for POLE mutation analysis, should be integrated into conventional pathologic diagnosis.

\section{Conclusions}

The VBT boost is a part of adjuvant pelvic RT, including concomitant CRT combined with four cycles of carboplatin/paclitaxel CT. This strategy is widely accepted and recommended by international guidelines. However, combined irradiation for patients with early-stage disease with HR features and advanced disease, has never been verified in a randomized trial. Available evidence supports VBT alone as the adjuvant treatment of choice for patients with stage I EC with HIR features or occult stage II disease. It provides equivalent vaginal control with a lower risk of toxicity compared to pEBRT. VBT alone was a more non-toxic alternative to combined RT in the adjuvant treatment in a trial that enrolled patients defined as medium-risk. The superiority of VBT combined with three cycles of carboplatin/ paclitaxel CT over the standard pEBRT in early-stage EEC with HI- and HR features, was not demonstrated. Besides proper pathology, incorporation of additional (including molecular) risk 
Table 5. The role of vaginal cuff brachytherapy in the adjuvant therapy by the European Society of Gynecological Oncology/European Society for Radiotherapy and Oncology/European Society of Pathology (ESGO/ ESTRO/ESP) 2021 guidelines for the management of patients with endometrial carcinoma [9]

\begin{tabular}{|c|c|c|c|c|c|}
\hline $\begin{array}{l}\text { FIGO } \\
\text { stage } \\
(2009)\end{array}$ & $\begin{array}{c}\text { Histology/ } \\
\text { grade }\end{array}$ & LVSI $^{\mathrm{a}}$ & $\begin{array}{l}\text { Risk } \\
\text { group }\end{array}$ & Adjuvant therapy options $\left({ }^{\star}\right),{ }^{\star *}$ & VBT indications $\left(^{*}\right)$ \\
\hline \multirow[t]{2}{*}{ IA } & $\begin{array}{l}\mathrm{EEC} \\
\mathrm{G} 1-2\end{array}$ & No/focal & $L R$ & $\begin{array}{l}\text { No adjuvant treatment is recommended } \\
\qquad(\mathrm{I}, \mathrm{A})\end{array}$ & \\
\hline & & Substantial & HIR & $\begin{array}{l}\text { pNO - EBRT can be considered (I, B); } \\
\text { CT can be considered; Omission of any }\end{array}$ & $\begin{array}{l}\text { pNO - adjuvant VBT is recommended to } \\
\text { decrease vaginal recurrence (II, B) }\end{array}$ \\
\hline
\end{tabular}

adjuvant treatment is an option ${ }^{c}$ CNO/pNX - EBRT is recommended (I, A);

Additional CT can be considered (II, B)

\begin{tabular}{|c|c|c|c|c|c|}
\hline & $\begin{array}{l}\text { EEC } \\
\text { G3 }\end{array}$ & No/focal & IR & VBT (I, A) or no adjuvant treatment (III, C) & $\begin{array}{c}\text { VBT alone (I, A); Omission of VBT can be } \\
\text { considered (III, C), especially for patients } \\
\text { aged }<60 \text { years (II, A) }\end{array}$ \\
\hline & & Substantial & $H I R$ & $\begin{array}{l}\text { pNO - EBRT can be considered (I, B); } \\
\text { CT can be considered; Omission of any } \\
\text { adjuvant treatment is an option } \\
\text { cNO/pNX - EBRT is recommended (I, A); } \\
\text { Additional CT can be considered (II, B) }\end{array}$ & $\begin{array}{l}\text { pNO - adjuvant VBT is recommended to } \\
\text { decrease vaginal recurrence (II, B) }\end{array}$ \\
\hline \multirow[t]{3}{*}{ IB } & $\begin{array}{l}\mathrm{EEC} \\
\mathrm{G} 1-2\end{array}$ & No/focal & IR & VBT $(I, A)$ or no adjuvant treatment (III, C) & $\begin{array}{c}\text { VBT alone (I, A); } \\
\text { Omission of VBT can be considered (III, C), } \\
\text { especially for patients aged < } 60 \text { years } \\
(\text { (II, A) }\end{array}$ \\
\hline & & Substantial & HIR & $\begin{array}{l}\text { pNO - EBRT can be considered (I, B); CT } \\
\text { can be considered (II, C); Omission of any } \\
\text { adjuvant treatment is an option (IV, C) } \\
\text { cNO/pNX - EBRT is recommended (I, A); } \\
\text { Additional CT can be considered (II, B) }\end{array}$ & $\begin{array}{l}\text { pNO - adjuvant VBT is recommended to } \\
\text { decrease vaginal recurrence (II, B) }\end{array}$ \\
\hline & $\begin{array}{l}\text { EEC } \\
\text { G3 }\end{array}$ & Any LVSI & HIR & $\begin{array}{l}\text { pNO - EBRT can be considered for sub- } \\
\text { stantial LVSI (I, B); CT can be considered, } \\
\text { especially for substantial LVSI (II, C) } \\
\text { Omission of any adjuvant treatment is an } \\
\text { option (IV, C) } \\
\text { CNO/pNX - EBRT is recommended, espe- } \\
\text { cially for substantial LVSI (I, A); Additional } \\
\text { CT can be considered, especially for } \\
\text { substantial LVSI (II, B) }\end{array}$ & $\begin{array}{l}\text { pNO - adjuvant VBT is recommended to } \\
\text { decrease vaginal recurrence (II, B) } \\
\text { cNO/pNX - VBT alone can be considered } \\
\text { for LVSI negative (II, B) }\end{array}$ \\
\hline$\|$ & EEC & Any LVSI & HIR & $\begin{array}{l}\text { pNO - EBRT can be considered (I, B); CT } \\
\text { can be considered especially for G3 and/ } \\
\text { or substantial LVSI (II, C); Omission of any } \\
\text { adjuvant treatment is an option (IV, C) } \\
\text { cNO/pNX - EBRT is recommended (I, A); } \\
\text { Additional CT can be considered, espe- } \\
\text { cially for G3 and/or substantial LVSI (II, B) }\end{array}$ & $\begin{array}{l}\text { pNO - adjuvant VBT is recommended to } \\
\text { decrease vaginal recurrence (II, B) } \\
\text { cNO/pNX - VBT alone can be considered } \\
\text { for G3 LVSI negative and for G1 (II, B) }\end{array}$ \\
\hline III, IVA & EEC & Any LVSI & $\mathrm{HR}$ & $\begin{array}{l}\text { EBRT + concurrent and adjuvant or se- } \\
\text { quential CT are recommended (I, B); } \\
\text { CT alone is an alternative option (I, B) }\end{array}$ & $\begin{array}{c}\text { VBT boost can be considered, especially } \\
\text { for substantial LVSI, endocervical stromal } \\
\text { invasion, and/or stage IIIB, IIIC }\end{array}$ \\
\hline $\begin{array}{l}\text { IA, } \\
\text { no } M \mid\end{array}$ & NEEC & Any LVSI & IR & $\begin{array}{l}\text { VBT only or CT (with or without VBT); } \\
\text { Omission of VBT can be considered (III, C) }\end{array}$ & \\
\hline $\begin{array}{l}\text { I, II, III, } \\
\text { IVA }\end{array}$ & NEEC & Any LVSI & $\mathrm{HR}$ & $\begin{array}{l}\text { EBRT + concurrent and adjuvant or se- } \\
\text { quential CT are recommended; CT alone } \\
\text { is an alternative option }\end{array}$ & $\begin{array}{c}\text { VBT boost can be considered, especially } \\
\text { for substantial LVSI, endocervical stromal } \\
\text { invasion, and/or stage IIIB, IIIC }\end{array}$ \\
\hline
\end{tabular}

EEC - endometrioid endometrial cancer, NEEC - non-endometrioid endometrial cancer, LVSI - lymphovascular space invasion, LR - low-risk, HIR - high-intermediate-risk, IR-intermediate-risk, HR - high-risk, $p N O$ - surgical nodal staging performed, node negative, $p N X$ - no surgical nodal staging performed, EBRT - external beam radiotherapy, CT - chemotherapy, MI - myometrial invasion, VBT - vaginal cuff brachytherapy, a substantial LVSI defined as multifocal or diffuse arrangement of LVSI or the presence of tumor cells in five or more lymphovascular spaces, b risk groups by ESGO/ESTRO/ESP, " only when close follow-up is guaranteed to ensure detection and prompt treatment of recurrence at an early stage, *levels of evidence, grades of recommendations according to an adapted version of the Infectious Diseases Society of America-United States Public Health Service Grading System, **in case of known molecular classification: for stage I, II POLEmut (polymerase mutated) - omission of adjuvant treatment should be considered, for p53abn (p53 abnormal) carcinomas restricted to a polyp or without MI, adjuvant therapy is generally not recommended, p53abn carcinomas with MI should be considered as HR 
factors may improve the current risk classification of EC, enabling identification of patients who may benefit the most from particular forms of adjuvant therapy, including VBT.

What is of significance, as compared to other common malignancies, there have been relatively few randomized trials addressing the post-operative therapy in EC. Further, there has been significant clinical heterogeneity of enrolled cohorts, regarding clinical risk, such as tumor histology (NEEC for sub-set analysis was not adequately powered) and grade, the extent of surgical nodal staging form, and the features of CT. Modern RT techniques, including image-guided BT, highly conformal EBRT using IMRT, and volumetric modulated arc therapy, were not available in the majority of trials. In consequence, the current guidelines of the ESMO/ESGO/ESTRO, NCCN and ESGO/ESTRO/ESP for adjuvant therapy in EC patients show some differences $[2,9,29,44]$. Currently, recommendations for the use of both exclusive and adjuvant VBT depends on the individual assessment of the risk of relapse, which includes FIGO stage, grade, histologic type, LVSI status, the performed surgical nodal staging, and age. The indications for VBT according to the ESGO/ ESTRO/ESP 2021 guidelines for the management of EC patients, which constitute a statement of evidence and consensus of the authors regarding their views of currently accepted approaches for EC treatment, are presented in Table 5.

\section{Disclosure}

The authors report no conflict of interest.

\section{References}

1. Bray F, Ferlay J, Soerjomataram I et al. Global Cancer Statistics 2018: GLOBOCAN Estimates of Incidence and Mortality Worldwide for 36 Cancers in 185 Countries. CA Cancer J Clin 2018; 68: 394-424

2. Colombo N, Creutzberg C, Amant F et al. ESMO-ESGO-ESTRO Endometrial Consensus Conference Working Group. ESMO-ESGO-ESTRO Consensus Conference on Endometrial Cancer: diagnosis, treatment and follow-up. Ann Oncol 2016; 27: 16-41.

3. Benedetti Panici P, Basile S, Maneschi F et al. Systematic pelvic lymphadenectomy vs. no lymphadenectomy in early-stage endometrial carcinoma: randomized clinical trial. J Nat Cancer Inst 2008; 100: 1707-1716.

4. Kitchener H, Swart AM, Qian Q et al. Efficacy of systemic pelvic lymphadenectomy in endometrial cancer (MRC ASTEC trial): A randomised study. Lancet 2009; 373: 125-136.

5. Holloway RW, Abu-Rustum NR, Backers FJ et al. Sentinel lymph node mapping and staging in endometrial cancer: A Society of Gynecologic Oncology literature review with consensus recommendations. Gynecol Oncol 2017; 146: 405-415.

6. Rossi EC, Kowalski LD, Scalici J et al. A comparison of sentinel lymph node biopsy to lymphadenectomy for endometrial cancer staging (FIRES trial): a multicentre, prospective, cohort study. Lancet Oncol 2017; 18: 384-392.

7. Creutzberg CL, van Putten WL, Koper PC et al. Surgery and postoperative radiotherapy versus surgery alone for patients with stage-1 endometrial carcinoma; multicentre randomised trial. PORTEC Study Group. Post Operative Radiation Therapy in Endometrial Carcinoma. Lancet 2000; 355: 1404-1411.
8. Keys HM, Roberts JA, Brunetto VL et al. A phase III trial of surgery with or without adjuvant external pelvic radiation therapy in intermediate risk endometrial adenocarcinoma. A Gynecologic Oncology Group Study. Gynecol Oncol 2004; 92: 744-751.

9. Concin N, Matias-Quiu X, Vergote I et al. ESGO/ESTRO/ ESP guidelines for the management of patients with endometrial carcinoma. Int J Gynecol Cancer 2021; 31: 12-39.

10. Randall ME, Filiaci V, McMeelcin DS et al. Phase III trial; adjuvant pelvic radiation therapy versus vaginal brachytherapy plus paclitaxel/carboplatin in high-intermediate and high-risk early stage endometrial cancer. J Clin Oncol 2019; 37: 1810-1819.

11. Aalders J, Abeler V, Kolstad P et al. Postoperative external irradiation and prognostic parameters in stage i endometrial carcinoma: clinical and histopathologic study of 540 patients. Obstet Gynecol 1980; 56: 419-427.

12. Blake P, Swart AM, Orton J et al. Adjuvant external beam radiotherapy in treatment of endometrial cancer (MRC ASTEC and NCIC CTG EN.5 randomised trial): pooled trial results, systematic review, and meta-analysis. Lancet 2009; 373: 137-146.

13. Creutzberg CL, Nout RA, Lybert ML et al. Fifteen-year radiotherapy outcome of the randomized PORTEC-1 trial for endometrial carcinoma. Int J Radiat Oncol Biol Phys 2011; 81: 631-638.

14. Scholten AN, van Putten WLJ, Beerman H et al. Postoperative radiotherapy for stage I endometrial carcinoma: Long-term outcome of the randomized PORTEC trial with central pathology review. Int J Radiat Oncol Biol Phys 2005; 63: 834-838.

15. Kuopalla T, Maenpaa J, Tomas E et al. Surgically staged highrisk endometrial cancer: randomized study of adjuvant radiotherapy alone vs. sequential chemo-radiotherapy. Gynecol Oncol 2008; 110: 190-195.

16. Maggi R, Lissoni A, Spina F et al. Adjuvant chemotherapy vs radiotherapy in high-risk endometrial carcinoma: results of a randomised trial. Br J Cancer 2006; 95: 266-271.

17. Susumu N, Sagae S, Udagawa Y et al. Randomized phase III trial of pelvic radiotherapy versus cisplatin-based combined chemotherapy in patients with intermediate- and high-risk endometrial cancer: a Japanise Gynecologic Oncology Group study. Gynecol Oncol 2008; 108: 226-233.

18. Hogberg T, Signorelli M, de Oliveira CF et al. Sequential adjuvant chemotherapy and radiotherapy in endometrial cancer - results from two randomised studies. Eur J Cancer 2010; 46: 2422-2431.

19. De Boer SM, Powell ME, Mileshkin L et al. Toxicity and quality of life after adjuvant chemoradiotherapy versus radiotherapy alone for women with high-risk endometrial cancer (PORTEC-3): an open-label, multicentre, randomised, phase 3 trial. Lancet Oncol 2016; 17: 1114-1126.

20. De Boer SM, Powell ML, Mileshkin L et al. Adjuvant chemoradiotherapy versus radiotherapy alone for women with high-risk endometrial cancer (PORTEC-3: final results of an international, open-label, multicentre, randomised, phase 3 trial. Lancet Oncol 2018; 19: 295-309.

21. De Boer SM, Powell ML, Mileshkin L et al. Adjuvant chemoradiotherapy versus radiotherapy alone in women with high-risk endometrial cancer (PORTEC-3: patterns of recurrence and post-hoc survival analysis of a randomised phase 3 trial. Lancet Oncol 2019; 20: 1273-1285.

22. Matei D, Filiaci V, Randall ME et al. Adjuvant chemotherapy plus radiation for locally advanced endometrial cancer. N Engl J Med 2019; 380: 2317-2326.

23. Sorbe B, Nordstrom B, Maenpaa J et al. Intravaginal brachytherapy in FIGO I low-risk endometrial cancer. A controlled randomized study. Int J Gynecol Cancer 2009; 19: 873-878.

24. Nout RA, Smit VT, Putter H et al. PORTEC Study Group. Vaginal brachytherapy versus pelvic external beam radio- 
therapy for patients with endometrial cancer of high-intermediate risk (PORTEC-2): an open-label, non-inferiority, randomised trial. Lancet 2010; 375: 816-823.

25. De Boer SM, Nout RA, Jurgenliemk-Schulz IM et al. Longterm impact of endometrial cancer diagnosis and treatment on health-related quality of life and cancer survivorship: results from the randomiszed PORTEC-2 trial. Int I Radiat Oncol Biol Phys 2015; 93: 797-808.

26. Wortman BG, Creutzberg CL, Putter $\mathrm{H}$ et al. Ten-year results of the PORTEC-2 trial for high-intermediate risk endometrial carcinoma: improving patient selection for adjuvant therapy. Br J Cancer 2018; 119: 1067-1074.

27. Sorbe B, Horvath G, Andersson H et al. External pelvic and vaginal irradiation versus vaginal irradiation alone as postoperative therapy in medium-risk endometrial carcinoma a prospective randomized study. Int J Radiat Oncol Biol Phys 2012; 82: 1249-1255.

28. Sorbe B, Horvath G, Andersson $H$ et al. External pelvic and vaginal irradiation versus vaginal irradiation alone as postoperative therapy in medium-risk endometrial carcinoma: a prospective, randomized study - quality-of-life analysis. Int J Gynecol Cancer 2012; 22: 1281-1288.

29. National Comprehensive Cancer Network Clinical Practice Guidelines in Oncology Uterine Neoplasms. Version 2. 2020. Available from https://www.nccn.org/professionals/physician_gls/pdf/uterine.pdf (accessed: 30 Aug 2020).

30. Albuquerque K, Hrycushko BA, Harkenrider MM et al. Compendium of fractionation choices for gynecologic HDR brachytherapy - an American Brachytherapy Society Task Group Report. Brachytherapy 2019; 18: 429-436.

31. Delishaj D, Barcellini A, D'Amico R et al. Vaginal toxicity after high-dose-rate endovaginal brachytherapy: 20 years of results. J Contemp Brachytherapy 2018; 10: 559-566.

32. Harkenrider MM, Block AM, Alektiar KM et al. American Brachytherapy Task Group Report: Adjuvant vaginal brachytherapy for early-stage endometrial cancer: A comprehensive review. Brachytherapy 2017; 16: 95-108.

33. Alektiar KM, Venkatraman E, Chi DS et al. Intravaginal brachytherapy alone in intermediate-risk endometrial cancer. Int J Radiat Oncol Biol Phys 2005; 62: 111-117.

34. De Sanctis V, Musio D, de Felice F et al. One-week vaginal brachytherapy schedule as exclusive adjuvant post-operative treatment in intermediate- and high-intermediate-risk endometrial cancer patients. J Contemp Brachytherapy 2020; 12: $124-130$.

35. Horowitz NS, Peters WA, Smith MR et al. Adjuvant high dose rate vaginal brachytherapy as treatment of stage I and II endometrial carcinoma. Obstet Gynecol 2002; 99: 235-240.

36. Laliscia C, Delishaj D, Fabrini MG et al. Acute and late vaginal toxicity after adjuvant high-dose-rate vaginal brachytherapy in patients with intermediate risk endometrial cancer: is local therapy with hyaluronic acid of clinical benefit? J Contemp Brachytherapy 2016; 8: 512-517.

37. Landrum LM, Nugent EK, Zuna RE et al. Phase II trial of vaginal cuff brachytherapy followed by chemotherapy in early stage endometrial cancer patients with high-intermediate risk factors. Gynecol Oncol 2014; 132: 50-54.

38. Sunil RA, Bhavsar D, Shruthi MN et al. Combined external beam radiotherapy and vaginal brachytherapy versus vaginal brachytherapy in stage I, intermediate-and high-risk cases of endometrium carcinoma. J Contemp Brachytherapy 2018; 10: 105-114.

39. De Boer SM, Wortman BG, Bosse T et al. Clinical consequences of upfront pathology review in the randomised PORTEC-3 trial for high-risk endometrial cancer. Ann Oncol 2018; 29: 424-430.
40. Guntupalli SR, Zighelboim I, Kizer NT et al. Lymphovascular space invasion is an independent risk factor for nodal disease and poor outcomes in endometrioid endometrial cancer. Gynecol Oncol 2012; 124: 31-35.

41. Bosse T, Peters EF, Creutzberg CL et al. Substantial lymph-vascular space invasion (LVSI) is a significant risk factor for recurrence in endometrial cancer - A pooled analysis of PORTEC 1 and 2 trials. Eur J Cancer 2015; 51: 1742-1750.

42. Cancer Genome Atlas research Network, Kandoth C, Schultz N et al. Integrated genomic characterization of endometrial carcinoma. Nature 2013; 497: 67-73.

43. Talhouk A, McConechy MK, Leung S et al. Confirmation of ProMisE: a simple, genomics-based clinical classifier for endometrial cancer. Cancer 2017; 123: 802-813.

44. Colombo N, Creutzberg C, Querleu D et al., on behalf of the ESMO Guidelines Committee, eUpdate - Endometrial Cancer Algorithms, https://www.esmo.org/guidelines/ gynaecological-cancers/endometrial-cancer/esmo-esgo-estro-consensus-conference-on-endometrial-cancer/eupdate-endometrial-cancer-algorithms (accessed: 30 Dec 2020). 